\title{
Immune regulation by protein ubiquitination: roles of the E3 ligases VHL and Itch
}

\author{
Daisuke Aki ${ }^{1,2}$, Qian $\mathrm{Li}^{1}$, Hui Li ${ }^{1}$, Yun-Cai Liu ${ }^{1,2 \bowtie}$, Jee Ho Lee ${ }^{2 \bowtie}$ \\ ${ }^{1}$ Institute for Immunology, Tsinghua-Peking Center for Life Sciences, School of Medicine, Tsinghua University, Beijing 100084, \\ China \\ 2 La Jolla Institute for Allergy and Immunology, La Jolla, CA 92037, USA \\ $\bowtie$ Correspondence: yuncai_liu@mail.tsinghua.edu.cn (Y.-C. Liu), jhlee@lji.org (J. H. Lee) \\ Received September 26, 2018 Accepted October 23, 2018
}

\begin{abstract}
Protein ubiquitination is an important means of posttranslational modification which plays an essential role in the regulation of various aspects of leukocyte development and function. The specificity of ubiquitin tagging to a protein substrate is determined by E3 ubiquitin ligases via defined E3-substrate interactions. In this review, we will focus on two E3 ligases, VHL and Itch, to discuss the latest progress in understanding their roles in the differentiation and function of $\mathrm{CD}^{+} \mathrm{T}$ helper cell subsets, the stability of regulatory $T$ cells, effector function of $\mathrm{CD}^{+} \mathrm{T}$ cells, as well as the development and maturation of innate lymphoid cells. The biological implications of these E3 ubiquitin ligases will be highlighted in the context of normal and dysregulated immune responses including the control of homeostasis, inflammation, auto-immune responses and anti-tumor immunity. Further elucidation of the ubiquitin system in immune cells will help in the design of new therapeutic interventions for human immunological diseases and cancer.
\end{abstract}

KEYWORDS ubiquitin, E3 ligase, VHL, HIF, Itch, WWP2, Cbl-b, inflammation, autoimmunity

\section{INTRODUCTION}

Our immune system is tightly regulated to protect against invading pathogens, and at the same time to prevent from self-destruction. The immune responses are dependent on numerous cellular signaling pathways and their cross-interactions in immune cells. To achieve the selectivity and diversity of each pathway, post-translational modification plays an important role in regulating the function of key proteins during signal transduction cascades. The tagging of a small 76 amino acid polypeptide to a protein, known as protein ubiquitination, is an essential post-translational modification. Protein ubiquitination is carried out via a sequential enzymatic cascade by $E 1$ ubiquitin-activating enzymes, E2 ubiquitin-conjugating enzymes and E3 ubiquitin ligases (Komander, 2009). The E3 ligases determine the specificity by selectively recruiting particular protein substrates via defined protein-protein interactions. The E3 ligases can be classified into two classes. One is the RING (really interesting new gene)-type E3 ligases and the other is the HECT (homologous to the E6AP carboxyl terminus)-type E3 ligases, depending on the structure of specific E2 binding domains. The RING-type E3 ligase utilizes the RING domains to recruit and activate the ubiquitin-conjugated E2 enzymes to transfer ubiquitin to the substrate, whereas in the HECT-type E3 ligase, the HECT domain accepts ubiquitin on its cysteine residue from the E2 enzyme, and then directly transfers the ubiquitin to the specific substrate (Lorick et al., 1999; Metzger et al., 2012).

Protein ubiquitination plays an important role in diverse cellular responses such as cell cycle, signal transduction pathway, transcriptional regulation, DNA repair and apoptosis (Gilberto and Peter, 2017). In the immune system, ubiquitin-tagged modification has been implicated in both innate and adaptive immune responses (Liu, 2004). Particularly, E3 ligases have been shown to regulate the development, differentiation and activation of various leukocytes, and their biological functions. In this review, we will focus on two E3 ligases, the von Hippel-Lindau (VHL) and Itch, to discuss the latest new findings in the cellular and molecular mechanisms by which they control immune homeostasis under steady state and how the loss of them causes immune dysregulation under pathological conditions. 


\section{The E3 ligase VHL}

In humans, inactivation or mutation of the von Hippel-Lindau (VHL) gene results in tumor development in multiple tissues including the kidneys, pancreas, retina, uterus, central nervous system and the adrenal gland (Kaelin and Maher, 1998; Kim and Kaelin, 2004). The VHL E3 ligase complex is composed of elongin $\mathrm{B}$, elongin $\mathrm{C}$, cullin 2 and ring box protein 1 (Rbx1) (Kamura et al., 1999; Stebbins et al., 1999)

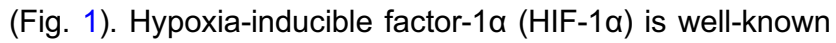
as a substrate of the VHL E3 ligase complex and is a master transcription factor that regulates the gene expression for glucose metabolism and angiogenesis at low oxygen levels (Zhang et al., 2007). HIF-1a is recognized as an oxygen sensor and thus plays an important role in adaptations to hypoxia. Although most mammalian cells show the constitutive expression of HIF-1a mRNA (Kallio et al., 1997), HIF-
$1 \alpha$ protein is maintained at a low level under normoxia, due to its hydroxylation by prolyl hydroxylase domain (PHD) enzymes, the recognition by $\mathrm{VHL}$, and the subsequent degradation by proteasome (Maxwell et al., 1999; Ivan et al., 2001). Under hypoxic conditions, PHD activity is reduced, which prevents the binding of HIF-1a to VHL, and thus leads to the accumulation of HIF-1 $\alpha$ thereby promoting the transcriptional activation of various genes. This biochemically well-defined oxygen-sensing VHL-HIF pathway, whose discovery leads to the 2016 Lasker award, plays an important role in the regulation of immune cells.

\section{VHL in T cells}

During $\mathrm{T}$ cell development, hematopoietic progenitor cells migrate from bone marrow into the thymus, a primary lymphoid organ known to be under hypoxic conditions (Hale
Figure 1. VHL-HIF pathway. (A) Schematic structure of $\mathrm{VHL}$ protein shows that the $\beta$-domain binds to hydroxylated HIF-1 $\alpha$, whereas the $\alpha-$ domain is for the binding of key components in the E3 ligase complexes. (B) Under normoxic conditions, PHD hydroxylates HIF-1 $\alpha$, which is recognized and ubiquitinylated by $\mathrm{VHL}$, followed by degradation through the proteasome pathway. During hypoxia, non-hydroxylated HIF- $1 \alpha$ is able to escape from ubiquitination by $\mathrm{VHL}$, and thus accumulated HIF-1 $\alpha$ translocates into the nucleus to turn on the transcription of its target genes
A

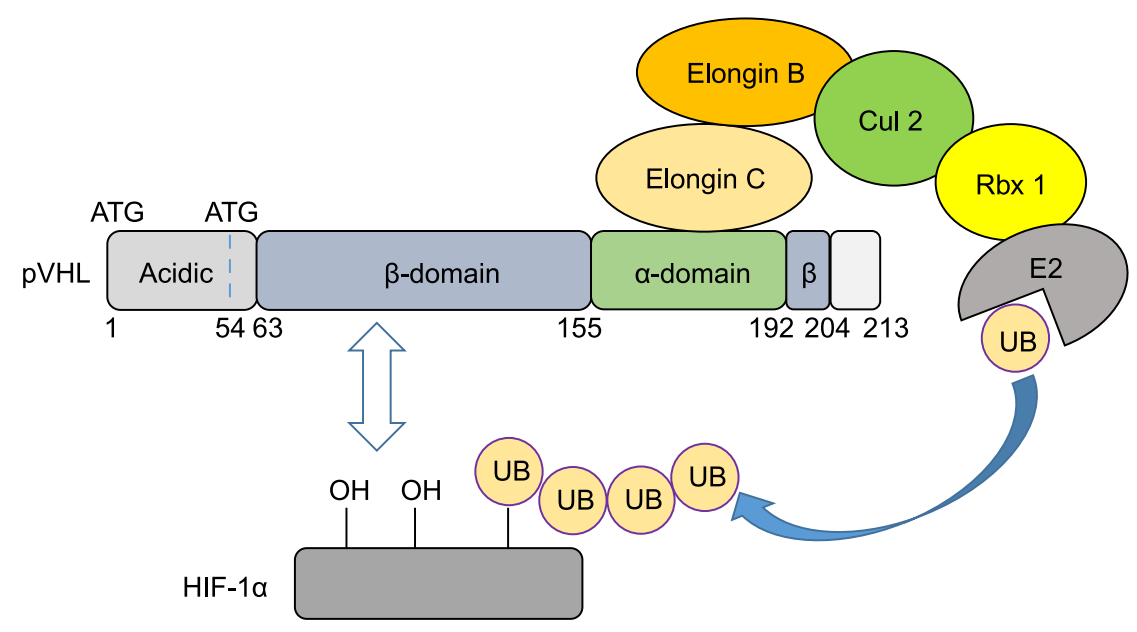

B

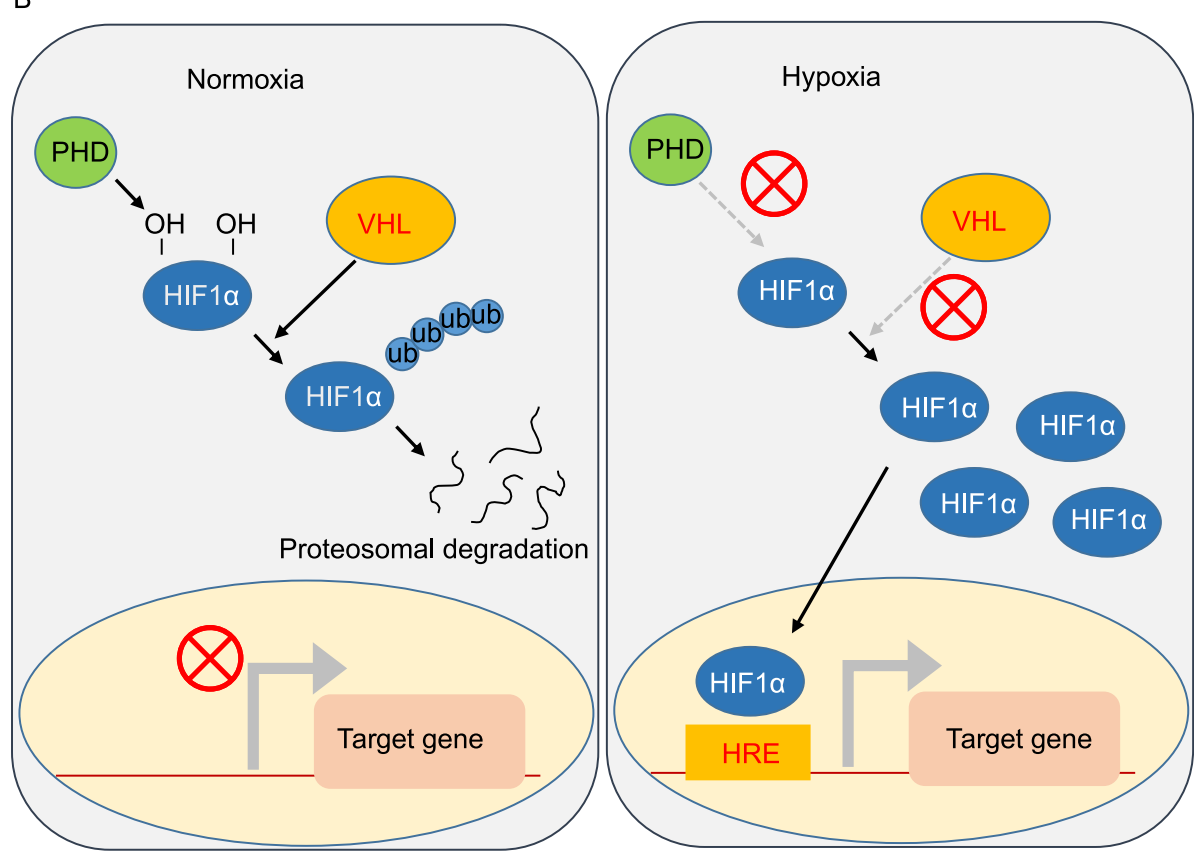


et al., 2002). The specific deletion of VHL has an impact on thymocyte development by inducing cell death through increased caspase activity (Biju et al., 2004). In addition, HIF-1 $\alpha$ induced by VHL deficiency regulates $\mathrm{Ca}^{2+}$ response upon $\mathrm{T}$ cell receptor (TCR) stimulation during thymocyte development (Neumann et al., 2005). Moreover, hypoxia can affect $\mathrm{T}$ cell differentiation in the peripheral tissues. Recent studies have demonstrated that HIF-1 $\alpha$ is a key transcription factor for T helper cell type 17 (Th17) and regulatory T cell (Treg) differentiation (Dang et al., 2011; Shi et al., 2011). HIF$1 \alpha$ is able to promote the gene expression of RORyt, a master transcription factor for Th17 cells, while suppressing Treg generation by downregulating Foxp3 (Dang et al., 2011). The HIF-1 $\alpha$-dependent glycolytic pathway is shown to regulate the balance of Th17 and Treg polarization by the utilization of a glycolytic inhibitor (Shi et al., 2011). On the contrary, other groups have reported that the HIF-1 $1 \alpha$ pathway promotes Foxp3 expression (Ben-Shoshan et al., 2008; Clambey et al., 2012). Thus, it remains unclear how the VHL/ HIF pathway regulates Treg development and/or function.

Our own study revealed that VHL controls Treg stability and function by regulating HIF-1 $\alpha$ by utilization of $V h f^{f / / f l}$ Foxp ${ }^{\text {cre }}$ conditional knockout mice (Lee et al., 2015). In VHL-deficient Treg cells, HIF-1a is able to induce the production of interferon- $\gamma$ (IFN- $\gamma$ ) by transcriptional activation by binding onto the Ifng gene locus. This further promotes Th1domininant inflammation in conditional VHL knockout mice. The induction of IFN- $\gamma$ by the VHL/HIF pathway is also required for glycolytic metabolism. Furthermore, a recent study reported that IFN-y-producing Treg cells regulated by neuropilin-1 promote anti-tumor immunity through hypoxia that controls Treg fragility via HIF-1a (Overacre-Delgoffe et al., 2017). Another recent study also showed that PHD protein restrains $\mathrm{T}$ cell-intrinsic anti-tumor immunity by the regulation of Th1 immune response (Clever et al., 2016). These findings suggest that the PHD/HIF/NHL pathway is responsible for IFN-y expression in Th1 immunity during tumor development as well as autoimmunity.

In addition, the VHL-HIF pathway is also involved in CD8 $\mathrm{T}$ cell development. $\mathrm{T}$ cell-specific $\mathrm{VHL}$ deletion in mice shows lethal pathology during persistent LCMV infection (Doedens et al., 2013). This is due to the fact that VHL deficiency-mediated HIF-1 $\alpha$ and HIF-2 $\alpha$ enhance the function of cytotoxic CD8 $T$ lymphocytes by promoting the expression of key transcription factors, effectors and costimulatory/inhibitory molecules. On the other hand, VHL-deficient cytotoxic T cells are more effective in preventing tumor growth with their enhanced cytotoxicity. Moreover, further study demonstrates that stable HIF-1 $\alpha$ by VHL deletion does not affect the differentiation of long-lived memory CD8 T cells although VHL deficiency sustains glycolytic metabolism. However, glycolytic metabolism promotes the differentiation of $\mathrm{T}$ effector memory cells, but not $\mathrm{T}$ central memory $\mathrm{CD} 8^{+}$ cells (Phan et al., 2016). This indicates that metabolic control by the VHL/HIF axis will be critical to generate protective $\mathrm{CD}^{+}$memory $\mathrm{T}$ cell against infections.

\section{VHL in B cells}

Bone marrow is known as a site with limited oxygen supply (Eliasson and Jonsson, 2010), and thus, it is likely that B cell development is regulated by hypoxia. Indeed, the absence of HIF-1 $\alpha$ leads to impaired $B$ cell development in the bone marrow due to defective proliferation of HIF-1a-deficient B cells. It has been noted that activated $B$ cells produce interleukin-10 (IL-10) to inhibit autoimmunity by suppressing pathogenic T cells (Nakashima et al., 2010; Matsumoto et al., 2014) and HIF-1 $\alpha$ deficiency results in an increased B1-like cell population which further causes autoimmunity (Kojima et al., 2002). HIF-mediated glycolysis suppresses the expression of IL-10 from CD1 $\mathrm{d}^{\text {hi }} \mathrm{CD}^{+} \mathrm{B}$ cells. HIF-1a and STAT3 cooperatively regulate IL-10 expression. Compared to WT control mice, HIF-1 1 -deficient mice are more susceptible to autoimmune diseases such as arthritis and experimental autoimmune encephalomyelitis (Evans et al., 2007; Matsushita et al., 2008). HIF-1a knockout B cells restrain Th1 and Th17 differentiation through IL-10 production (Meng et al., 2018). These findings support that the regulation of hypoxia is critical for $B$ cell function in preventing autoimmunity.

More interestingly, hypoxia in the germinal center (GC) regulates antibody production by $\mathrm{B}$ cells. HIF-1 $\alpha$ limits the proliferation, survival and isotype switching (Abbott et al., 2016). Low oxygen tension or B cell-specific VHL depletion restrains mTORC1 activity, thus inhibiting $B$ cell activation, which is restored by HIF-1 1 deletion, indicating that the $\mathrm{VHL}$ / HIF pathway plays an important role in antibody production in the GC during immune responses (Cho et al., 2016). These findings suggest that oxygen sensing through the VHL-HIF pathway is essential to regulate humoral immunity in the lymphoid tissues.

\section{VHL in myeloid cells}

The VHL-HIF axis also has an impact on innate immunity (Rius et al., 2008; Palazon et al., 2014). In fact, hypoxia is able to promote the suppressive function of myeloid-derived suppressor cells with upregulated arginase-1 and iNOS expression, which is dependent on HIF-1a accumulation (Corzo et al., 2010). Another study demonstrates that low oxygen concentration suppresses neutrophil apoptosis through HIF-1 $\alpha$-dependent NF-KB signaling (Walmsley et al., 2005). Thus, these findings support that the VHL/HIF pathway plays an important role in the development and function of myeloid cells. A more recent study utilized conditional $\mathrm{VHL}$ knockout mice by crossing $\mathrm{Vhl}$ floxed and CD11c-cre mice (Izquierdo et al., 2018). Interestingly, alveolar macrophages (AMs) show immature phenotypes due to $\mathrm{VHL}$ deficiency with reduced self-renewal capacity, indicating that $\mathrm{VHL}$ is required for maturation of AMs. In addition, the surfactant handling activity by AMs is also decreased by VHL deficiency, indicating $\mathrm{VHL}$ is responsible for the function of AMs to clear pulmonary surfactant. Thus, these data suggest that 
Table 1. The major phenotype of VHL conditional knockout mice.

\begin{tabular}{|c|c|c|c|}
\hline Target cells & cKO mice & Phenotype & References \\
\hline Thymocytes & $V h f^{f / / f l}$ Lck-cre & $\begin{array}{l}\text { - increases cell death and caspase activity } \\
\text { - reduces TCR-mediated } \mathrm{Ca}^{2+} \text { signaling }\end{array}$ & $\begin{array}{l}\text { (Biju et al., 2004) } \\
\text { (Neumann et al., } \\
\text { 2005) }\end{array}$ \\
\hline CD4 Treg cell & Vhffl/fl Foxp3-cre & $\begin{array}{l}\text { - loss of Treg suppressive function } \\
\text { - IFN- } y \text {-mediated Th1 dominant inflammation }\end{array}$ & (Lee et al., 2015) \\
\hline CD8 cell & $V h f^{f / f l} d L c k-c r e$ & $\begin{array}{l}\text { - mortality in persistent viral infection } \\
\text { - promotes cytotoxic killing } \\
\text { - enhances } T_{\text {em }} \text { differentiation via glycolytic } \\
\text { metabolism }\end{array}$ & $\begin{array}{l}\text { (Doedens et al., } \\
\text { 2013) } \\
\text { (Phan et al., } \\
\text { 2016) }\end{array}$ \\
\hline B cell & $\begin{array}{l}\text { Transfer model with B cells from } \\
\qquad h f^{f / f f l} E R^{T 2} \text {-cre }\end{array}$ & $\begin{array}{l}\text { - reduced GC function } \\
\text { - defective in clonal expansion, Ab production }\end{array}$ & (Cho et al., 2016) \\
\hline Macrophage & $V h f^{f l / f l}$ Cd11c-cre & $\begin{array}{l}\text { - defective in alveolar macrophage maturation, self- } \\
\text { renewal, function }\end{array}$ & $\begin{array}{l}\text { (Izquierdo et al., } \\
\text { 2018) }\end{array}$ \\
\hline $\begin{array}{l}\text { Innate } \\
\text { lymphoid cell }\end{array}$ & Vhfl/fl Plzf-cre & $\begin{array}{l}\text { - defective in ILC2 differentiation } \\
\text { - downregulated ST2 expression by metabolic shift }\end{array}$ & (Li et al., 2018) \\
\hline
\end{tabular}

the VHL/HIF axis is essential in terminal differentiation, selfrenewal and function of AMs.

\section{VHL in innate lymphoid cells}

Innate lymphoid cells (ILCs) are a recently defined subset of lymphocytes that reside in peripheral tissues and are particularly abundant at barrier surfaces. ILCs are functionally divided into three subsets: group 1 ILCs including natural killer cells and IFN-Y producing ILC1s that depend on T-bet for their development; group 2 ILCs that produce type 2 inflammatory cytokines and require GATA3 and RORY; and group 3 ILCs that produce IL-17A and/or IL-22 and depend on RORyt (Spits et al., 2013). They originate from common lymphoid progenitors that commit to ILC precursors expressing the transcription factor PLZF, which have the capacity to differentiate into mature ILCs (Constantinides et al., 2014). However, whether the VHL-HIF pathway is involved in the regulation of ILCs remains elusive.

To address this issue, we generated $V h f^{f l / f l} P / z f^{\text {cre }}$ mice to selectively deplete the VHL gene in ILC precursors and demonstrated that $\mathrm{VHL}$ plays a pivotal and selective role in the development and function of ILC2s through the HIF-1 $\alpha$ pathway ( $\mathrm{Li}$ et al., 2018). ILC2s can respond to alarmin cytokines such as IL-33, IL-25 and TSLP to produce type 2 cytokines, thus playing a key role in allergic diseases, antihelminth infection and metabolic homeostasis (Ebbo et al., 2017). Conditional deletion of VHL in innate lymphoid precursors minimally affected early-stage bone marrow ILC2s, but caused a selective and intrinsic decrease in mature ILC2 numbers in peripheral non-lymphoid tissues such as the lung, intestine and lipid tissues, resulting in reduced type 2 immune responses. As expected, VHL deficiency caused

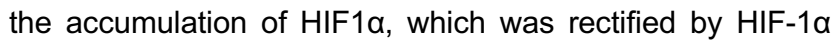
ablation. In addition, IL-33 receptor ST2 expression was attenuated in VHL-deficient ILC2s. Further mechanistic studies showed that the HIF-1a-driven metabolic shift altered the epigenetic modification on the ST2 gene and thus inhibited IL-33-induced ILC2 development.

Taken together, the VHL/HIF pathway is critical for the development and function of various immune cells (Table 1). Since hypoxia can affect diverse cells simultaneously in a tissue environment, further studies will investigate the mutual interplay between immune cells to understand the detailed mechanism for their function during inflammatory immune responses or tumor development.

\section{The E3 ligase Itch}

The HECT-type family of E3 ligases possess an intrinsic catalytic activity that mediates protein ubiquitination and are crucial for immune cell development and functions (Aki et al., 2015). Itch is a HECT-domain containing E3 ligase whose structure includes an N-terminal C2 domain which binds to $\mathrm{Ca}^{2+}$ and phospholipids and functions in targeting to the intracellular membrane, four WW domains which mediate specific interactions with target proteins, and a C-terminal ubiquitin-protein ligase HECT domain (Fig. 2). Itch catalyzes protein ubiquitination in two-steps: (1) the HECT ligase domain binds to the E2-ubiquitin complex and transfers the activated ubiquitin to a catalytic cysteine residue at its C-terminal region; (2) Itch catalyzes the ubiquitin transfer from the HECT domain to the lysine residues of the substrates. Itch, which belongs to the neuronal precursor cell expressed developmentally downregulated protein 4 (NEDD4) family, has been demonstrated to regulate immune responses, especially Th cell-mediated adaptive immunity (Table 2). The biological function of Itch on immunological homeostasis was initially described in the genetic study of mouse coat color gene mutation in 1995 (Hustad et al., 


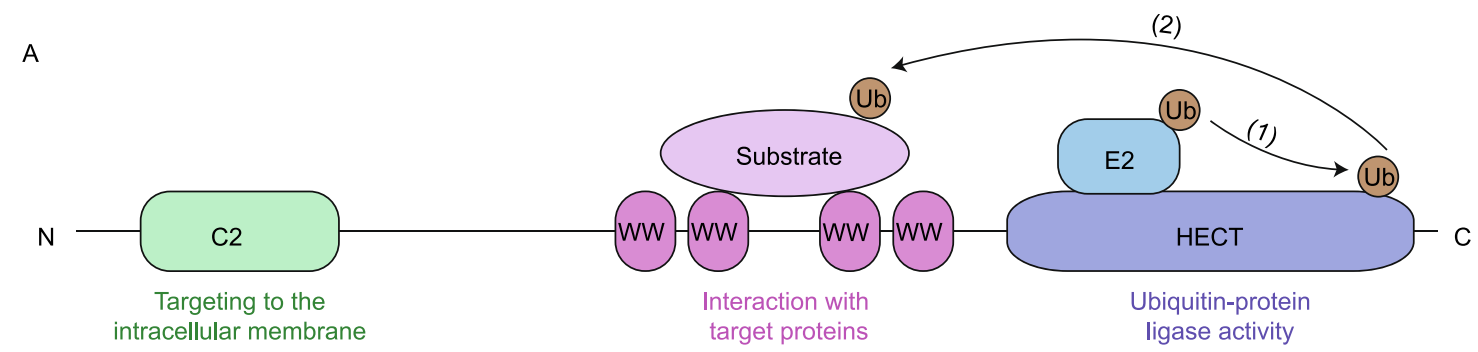

B

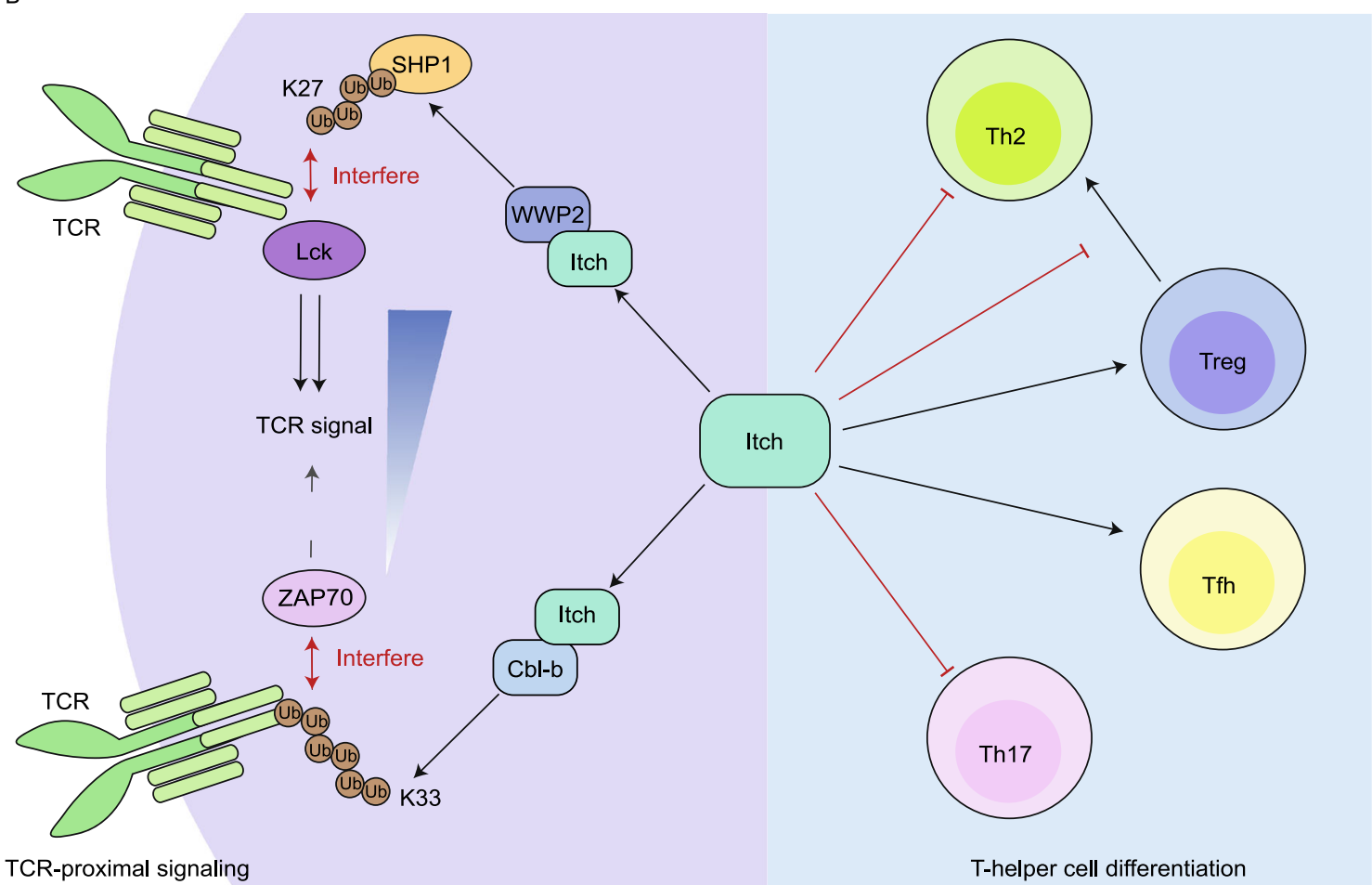

Figure 2. Itch and its role in T cells. (A) Schematic structure of Itch which shows the N-terminal C2 domain, the 4 WW domains for substrate recruitment, and the HECT ligase domain for the E2-ubiquitin binding and for the transfer of ubiquitin to the substrate. (B) Distinct functions of Itch in T cells. Itch cooperates with other E3 ligases to regulate TCR-proximal signaling (left). Itch regulates the differentiation of different $T$ helper subsets (right).

1995). The mutant mice, who were homozygous for one of the identified mutations which ablated the HECT domain containing protein expression, exhibited various immunological disorders and skin scratching due to the constant itching; thus this responsible gene product was named Itch (Hustad et al., 1995; Perry et al., 1998).

\section{Itch in T helper cells}

The multi-organ inflammation observed in Itchy $\left(\right.$ Itch $\left.^{-1-}\right)$ mice was associated with a spontaneous Th2-skewed immune phenotype that showed higher levels of immunoglobulin $\mathrm{E}$
(IgE) and $\lg \mathrm{G} 1$ in the serum compared to wild-type mice at 6 months of age (Fang et al., 2002). Indeed, Itch deficient $\mathrm{CD}^{+}{ }^{+} \mathrm{T}$ cells produced more Th2 specific cytokines such as IL-4 and IL-5, suggesting that Itch is a negative regulator of Th2 differentiation (Fang et al., 2002; Venuprasad et al., 2006).

Further studies revealed the function of Itch in different types of Th cells. We found that naive $\mathrm{CD}^{+} \mathrm{T}$ cells from Itchy mice show impaired inducible Treg generation cultured in the presence of TGF- $\beta$ (Venuprasad et al., 2008). Moreover, the study using mice with Treg-specific ablation of Itch by crossing Itch $^{\mathrm{fl} / \mathrm{fl}}$ mice to Foxp3 ${ }^{\mathrm{YFP}-\mathrm{Cre}}$ mice demonstrated 
Table 2. The major phenotype of Itch knockout mice.

\begin{tabular}{|c|c|c|c|}
\hline Target cells & cKO mice & Phenotype & References \\
\hline $\begin{array}{l}\text { Th2 cell } \\
\text { Inducible Treg } \\
\text { cell } \\
\text { Tfh cell } \\
\text { Th17 cell }\end{array}$ & $\mathrm{Itch}^{-1-}$ & $\begin{array}{l}\text { - increases IgE and IgG1 levels in the serum } \\
\text { - CD4 }{ }^{+} \mathrm{T} \text { cells produce more IL-4 and IL-5 } \\
\text { - impaired inducible Treg generation } \\
\text { - defective in Tfh differentiation } \\
\text { - elevated IL-17 expression in the colonic mucosa }\end{array}$ & $\begin{array}{l}\text { (Fang et al., 2002) } \\
\text { (Venuprasad et al., } \\
2006 \text { ) } \\
\text { (Venuprasad et al., } \\
\text { 2008) } \\
\text { (Xiao et al., 2014) } \\
\text { (Kathania et al., 2016) }\end{array}$ \\
\hline Treg cell & Itch $h^{\mathrm{fl} / \mathrm{fl}}$ Foxp $3^{\text {YFP-Cre }}$ & $\begin{array}{l}\text { - increases secretion of Th2 cytokines in Treg cells } \\
\text { - Th2-biased inflammation }\end{array}$ & (Jin et al., 2013) \\
\hline Tfh cell & $I t c h^{\mathrm{fl} / \mathrm{fl}}$ Cd4-cre & $\begin{array}{l}\text { - defective in Tfh differentiation in a FOXO1-dependent } \\
\text { manner }\end{array}$ & (Xiao et al., 2014), \\
\hline Th2 cell & $\begin{array}{l}\text { Itch }{ }^{\mathrm{fl} / \mathrm{fl}} \mathrm{Cd} 4-\mathrm{cre} \\
\quad W W P 2^{-/-}\end{array}$ & $\begin{array}{l}\text { - spontaneous development of autoimmunity and lung } \\
\text { inflammation } \\
\text { - enhances Th2 differentiation } \\
\text { - reduces TCR signal strength }\end{array}$ & (Aki et al., 2018) \\
\hline $\mathrm{CD}^{+}{ }^{+} \mathrm{T}$ cell & $\mathrm{Itch}^{-/-} \mathrm{Cblb}^{-/-}$ & $\begin{array}{l}\text { - spontaneous autoimmunity } \\
\text { - increases } T \text { cell signaling }\end{array}$ & (Huang et al., 2010) \\
\hline
\end{tabular}

that Itch deficient Treg cells have normal suppressive function. However, secretion of Th2 cytokines is augmented in those cells, and $I t c h^{\mathrm{fl} / \mathrm{fl}}$ Foxp $3^{\mathrm{YFP}-\mathrm{Cre}}$ mice show Th2-biased phenotypes (Jin et al., 2013). These findings suggest that Itch controls Th2 response by regulating Treg differentiation.

Follicular helper $\mathrm{T}$ (Tfh) cells are required for germinal center (GC) formation, affinity maturation of B cells, and generation of plasma and memory $B$ cells. Itch deficiency results in impairment of Tfh cell differentiation and GC responses to acute viral infection in a T-cell intrinsic manner (Xiao et al., 2014). A mechanistic study demonstrated that Itch has a function in ubiquitin-mediated protein degradation of Foxo1, which negatively regulates Tfh development (Xiao et al., 2014; Stone et al., 2015). In addition, it is also reported that Itchy mice exhibit spontaneous colonic inflammation and increased colitis-associated colon cancer due to a higher expression of IL-17 in Th17 cells (Kathania et al., 2016). Itch might negatively control Th17 differentiation through ubiquitination mediated by lysine 48 (K48) linkage and degradation of RORyt, which is the master regulator of Th17 differentiation. Consistent with this, Nedd4 family interacting protein 1 (NDFIP1), which activates the catalytic activity of Itch, also promoted RORyt degradation and reduced IL-17 production in Th17 cells (Layman et al., 2017).

\section{Itch cooperation with other E3 ligases}

Among NEDD4 E3s, Itch has a highly similar amino acid sequence to another member named WWP2, particularly in the WW domains that determine substrate recognition (Jiang et al., 2015; Aki et al., 2018). Recent structural and biochemical studies suggest that the molecular mechanisms by which catalytic activity of E3 is regulated are commonly employed between these two E3s (Riling et al., 2015; Chen et al., 2017; Zhu et al., 2017). Interestingly, it is demonstrated that some NEDD4 E3s recognize a common substrate and collaboratively function in cellular events via protein ubiquitination (Chaudhary and Maddika, 2014; Brigui et al., 2015; Chen et al., 2016). In spite of these findings, however, it has remained to be established whether Itch and WWP2 cooperate to regulate immune cells, especially Th cell development or function.

We recently generated Itch ${ }^{f l f l} C d 4^{C r e} W W P^{-/-}$(DKO) mice with T cells that lack both Itch and WWP2 expression. DKO mice exhibit spontaneous development of autoimmunity and lung inflammation, to an extent not observed in any single deficient mice (Aki et al., 2018). DKO CD4 ${ }^{+}$T cells demonstrated hypo-responsiveness upon TCR stimulation and striking Th2 skewing. Mechanistically, Itch and WWP2 form a complex and cooperate to enhance TCR-proximal signaling, catalyzing K27-linked ubiquitin chain conjugation to SHP-1. Although Itch and WWP2 mediated ubiquitination of SHP-1 affects neither protein stability nor phosphatase activity of SHP-1, it is required for inhibition of its binding to Lck, thus positively regulating TCR-mediated signal transduction. These findings indicate the cooperative function of Itch and WWP2 on Th2 differentiation via regulating TCR signal strength.

Beyond the NEDD4 family, Itch has been shown to function together with a distinct E3 family in $\mathrm{CD} 4^{+} \mathrm{T}$ cells. Cbl-b, which belongs to the family of RING finger domaincontaining $\mathrm{E} 3 \mathrm{~s}$, is shown to be involved in the regulation of TCR-mediated T cell activation (Bachmaier et al., 2000; Chiang et al., 2000). Interestingly both Itch and Cbl-b are upregulated during the induction of $T$ cell anergy, and loss of Itch or Cbl-b in $\mathrm{T}$ cells results in resistance to anergy induction (Heissmeyer et al., 2004; Jeon et al., 2004; Venuprasad et al., 2006). These two E3s might target PLCY1 
for ubiquitination and subsequent degradation (Heissmeyer et al., 2004). These studies indicate the functional collaboration of Itch and Cbl-b on T cell anergy-mediated peripheral tolerance. Further study clearly showed that Itch and Cbl-b collaboratively prevent autoimmunity in mice by negative regulation of peripheral $\mathrm{CD}^{+}{ }^{+} \mathrm{T}$ cell activation (Huang et al., 2010). Using a biochemical approach, we found that these two E3s interact with each other and cooperate to suppress proximal TCR signal transduction through promoting K33linked polyubiquitination of the TCR $\zeta$ chain in a proteolysis independent manner. Itch and $\mathrm{Cbl}-\mathrm{b}$ mediated ubiquitination of the TCR $\zeta$ chain inhibits the binding of TCR $\zeta$ to ZAP-70 and phosphorylation of ZAP70, which leads to negative regulation of TCR signaling.

Although loss of either Itch or its functional partner E3, such as WWP2 or Cbl-b, in T cells had minimal to no overt effects on the spontaneous development of autoimmunity and inflammation in comparison with the combined loss of two E3s, it still remains elusive as to whether there is a functional compensation for Itch deficiency by another E3 ligase(s), in particular, the other NEDD4 E3s that share a structural homology with Itch. It is possible that such E3s could form a heteromeric complex with, and be potentially substituted for Itch or WWP2 in $\mathrm{CD}^{+} \mathrm{T}$ cell activation. A recently developed approach that is based on an E3-ubiquitin fusion protein that enables co-purification of Itch with potential interacting proteins will identify the protein complex formed in vivo containing E3s, and provide evidence on how such distinct E3s cooperatively regulate homeostasis in $\mathrm{T}$ cells via protein ubiquitination (O'Connor et al., 2015). In addition, future works will be required to elucidate the precise mechanism by which several types of ubiquitin conjugation such as K27-or K33-linkage in cooperation with two E3s could selectively occur and impact the assembly of signaling molecules including their target protein.

\section{PERSPECTIVES}

Nearly two decades have passed since it was first identified that Cbl RING finger acts as a protein interacting domain to recruit an E2 ubiquitin-conjugating enzyme to promote transfer of the activated ubiquitin to itself or a substrate (Joazeiro et al., 1999). Significant progress has been made in many different aspects in the context of immune regulation. The availability of gene-targeted mice, particularly conditional knockout mice, has made it possible to dissect the roles of the E3 ligases in a particular immune cell type under specific experimental conditions. It is now understood that the same E3 ligase may function differently in different lymphocytes such as T cells vs. B cells, or different Th subsets such as Treg vs. Tfh cells. One explanation would be that the same E3 ligase may target different substrates in those cell types. It is also possible that these E3 ligases may exhibit unique activity by tagging the substrate in different ubiquitin linkages by using K27, K33, K48, or K63 residues.
In cells, one E3 ligase may not work alone, but form a complex with other E3 ligases to exert their biological functions.

In the case of the VHL-HIF pathway, different biological functions have been reported in the same cell sub-type, such as in Tregs. Lymphoid tissues are constantly exposed to hypoxic challenges under steady and inflamed conditions. Even in the same local environments such as the germinal center, a gradient of oxygen levels has been observed (Abbott et al., 2016; Cho et al., 2016; Jellusova et al., 2017). It is possible that the experimental conditions employed may differ in those studies such as in vitro vs. in vivo, or steady state vs. after infection, which likely give rise to different biological readouts. More importantly, the metabolic states of those cells can be another factor that determines the final cell fate.

Either mutation or deletion of $\mathrm{VHL}$ or Itch has profound impact in human diseases such as tumor formation due to VHL mutation (Kim and Kaelin, 2004) or multisystem autoimmune disorders due to Itch deletion (Lohr et al., 2010), indicating the critical roles of the two E3 ligases in controlling human cell functions. It is still to be learned how the phenotypes in human diseases can be recapitulated in mouse models. In addition, the underlying cellular and molecular mechanisms are still far from clear to fully explain the observed biological manifestations in humans. These outstanding questions will lay a strong basis for future studies, and such knowledge will eventually provide help for the treatment of human diseases such as inflammation, autoimmune diseases, and cancer.

\section{ACKNOWLEDGEMENTS}

We thank the contributions of past and current lab members for their efforts in the VHL and Itch projects, and Ms. S. el Baghdady for text editing. This work is supported by funding from MOST YFA0505802, NSFC81630041, NIH RO1Al123398 and R21Al122258. Daisuke Aki, Qian Li, Hui Li, Yun-Cai Liu and Jee Ho Lee declare that they have no conflict of interest.

\section{ABBREVIATIONS}

AM, alveolar macrophage; DKO, double knockout; GC, germinal center; HECT, homologous to the E6AP carboxyl terminus; HIF-1 $\alpha$, hypoxia-inducible factor-1 $\alpha$; IFN- $\gamma$, interferon- $\gamma$; Ig, immunoglobulin; IL, interleukin; ILC, innate lymphoid cell; mTORC1, mammalian target of rapamycin complex 1; NEDD4, neuronal precursor cell expressed developmentally downregulated protein 4; NDFIP1, NEDD4 family interacting protein 1; PHD, prolyl hydroxylase domain; PLC-y1, phospholipase c-y1; PLZF, promyelocytic leukemia zinc finger; Rbx1, ring box protein 1; RING, really interesting new gene; SHP-1, Src homology region 2 domain-containing phosphatase-1; RORyt, retinoid acid-related orphan receptor $y \mathrm{t}$; TCR, T cell receptor; Tfh, follicular helper T cell; TGF- $\beta$, transforming growth factor- $\beta$; Th, T helper cell type; Treg, regulatory T cell; VHL, von Hippel-Lindau; ZAP-70, zeta-chain associated protein-70. 


\section{OPEN ACCESS}

This article is distributed under the terms of the Creative Commons Attribution 4.0 International License (http://creativecommons.org/ licenses/by/4.0/), which permits unrestricted use, distribution, and reproduction in any medium, provided you give appropriate credit to the original author(s) and the source, provide a link to the Creative Commons license, and indicate if changes were made.

\section{REFERENCES}

Abbott RK, Thayer M, Labuda J, Silva M, Philbrook P, Cain DW, Kojima H, Hatfield S, Sethumadhavan S, Ohta A et al (2016) Germinal center hypoxia potentiates immunoglobulin class switch recombination. J Immunol 197:4014-4020

Aki D, Li H, Zhang W, Zheng M, Elly C, Lee JH, Zou W, Liu YC (2018) The E3 ligases Itch and WWP2 cooperate to limit TH2 differentiation by enhancing signaling through the TCR. Nat Immunol. 19:766-775

Aki D, Zhang W, Liu YC (2015) The E3 ligase itch in immune regulation and beyond. Immunol Rev 266:6-26

Bachmaier K, Krawczyk C, Kozieradzki I, Kong YY, Sasaki T, Oliveira-dos-Santos A, Mariathasan S, Bouchard D, Wakeham A, Itie $A$ et al (2000) Negative regulation of lymphocyte activation and autoimmunity by the molecular adaptor Cbl-b. Nature 403:211-216

Ben-Shoshan J, Maysel-Auslender S, Mor A, Keren G, George J (2008) Hypoxia controls CD4+CD25+ regulatory T-cell homeostasis via hypoxia-inducible factor-1alpha. Eur J Immunol 38:2412-2418

Biju MP, Neumann AK, Bensinger SJ, Johnson RS, Turka LA, Haase $\mathrm{VH}$ (2004) Vhlh gene deletion induces Hif-1-mediated cell death in thymocytes. Mol Cell Biol 24:9038-9047

Brigui A, Hofmann L, Arguelles C, Sanial M, Holmgren RA, Plessis A (2015) Control of the dynamics and homeostasis of the Drosophila Hedgehog receptor Patched by two C2-WW-HECTE3 Ubiquitin ligases. Open Biol 5:150112

Chaudhary N, Maddika S (2014) WWP2-WWP1 ubiquitin ligase complex coordinated by PPM1G maintains the balance between cellular p73 and DeltaNp73 levels. Mol Cell Biol 34:3754-3764

Chen Z, Jiang H, Xu W, Li X, Dempsey DR, Zhang X, Devreotes P, Wolberger C, Amzel LM, Gabelli SB et al (2017) A tunable brake for HECT ubiquitin ligases. Mol Cell 66(345-357):e346

Chen Z, Thomas SN, Bolduc DM, Jiang X, Zhang X, Wolberger C, Cole PA (2016) Enzymatic analysis of PTEN ubiquitylation by WWP2 and NEDD4-1 E3 ligases. Biochemistry 55:3658-3666

Chiang YJ, Kole HK, Brown K, Naramura M, Fukuhara S, Hu RJ, Jang IK, Gutkind JS, Shevach E, Gu H (2000) Cbl-b regulates the CD28 dependence of T-cell activation. Nature 403:216-220

Cho SH, Raybuck AL, Stengel K, Wei M, Beck TC, Volanakis E, Thomas JW, Hiebert S, Haase VH, Boothby MR (2016) Germinal centre hypoxia and regulation of antibody qualities by a hypoxia response system. Nature 537:234-238

Clambey ET, McNamee EN, Westrich JA, Glover LE, Campbell EL, Jedlicka P, de Zoeten EF, Cambier JC, Stenmark KR, Colgan SP et al (2012) Hypoxia-inducible factor-1 alpha-dependent induction of FoxP3 drives regulatory T-cell abundance and function during inflammatory hypoxia of the mucosa. Proc Natl Acad Sci USA 109:E2784-2793

Clever D, Roychoudhuri R, Constantinides MG, Askenase MH, Sukumar M, Klebanoff CA, Eil RL, Hickman HD, Yu Z, Pan JH et al (2016) Oxygen sensing by $T$ cells establishes an immunologically tolerant metastatic niche. Cell 166(1117-1131):e1114

Constantinides MG, McDonald BD, Verhoef PA, Bendelac A (2014) A committed precursor to innate lymphoid cells. Nature 508:397401

Corzo CA, Condamine T, Lu L, Cotter MJ, Youn JI, Cheng P, Cho HI, Celis E, Quiceno DG, Padhya Tet al (2010) HIF-1alpha regulates function and differentiation of myeloid-derived suppressor cells in the tumor microenvironment. J Exp Med 207:2439-2453

Dang EV, Barbi J, Yang HY, Jinasena D, Yu H, Zheng Y, Bordman Z, Fu J, Kim Y, Yen HR et al (2011) Control of T(H)17/T(reg) balance by hypoxia-inducible factor 1 . Cell 146:772-784

Doedens AL, Phan AT, Stradner MH, Fujimoto JK, Nguyen JV, Yang E, Johnson RS, Goldrath AW (2013) Hypoxia-inducible factors enhance the effector responses of CD8(+) T cells to persistent antigen. Nat Immunol 14:1173-1182

Ebbo M, Crinier A, Vely F, Vivier E (2017) Innate lymphoid cells: major players in inflammatory diseases. Nat Rev Immunol 17:665-678

Eliasson P, Jonsson Jl (2010) The hematopoietic stem cell niche: low in oxygen but a nice place to be. J Cell Physiol 222:17-22

Evans JG, Chavez-Rueda KA, Eddaoudi A, Meyer-Bahlburg A, Rawlings DJ, Ehrenstein MR, Mauri C (2007) Novel suppressive function of transitional 2 B cells in experimental arthritis. J Immunol 178:7868-7878

Fang D, Elly C, Gao B, Fang N, Altman Y, Joazeiro C, Hunter T, Copeland N, Jenkins N, Liu YC (2002) Dysregulation of $T$ lymphocyte function in itchy mice: a role for Itch in $\mathrm{TH} 2$ differentiation. Nat Immunol 3:281-287

Gilberto S, Peter M (2017) Dynamic ubiquitin signaling in cell cycle regulation. J Cell Biol 216:2259-2271

Hale LP, Braun RD, Gwinn WM, Greer PK, Dewhirst MW (2002) Hypoxia in the thymus: role of oxygen tension in thymocyte survival. Am J Physiol Heart Circ Physiol 282:H1467-1477

Heissmeyer V, Macian F, Im SH, Varma R, Feske S, Venuprasad K, Gu H, Liu YC, Dustin ML, Rao A (2004) Calcineurin imposes T cell unresponsiveness through targeted proteolysis of signaling proteins. Nat Immunol 5:255-265

Huang $\mathrm{H}$, Jeon MS, Liao L, Yang C, Elly C, Yates JR 3rd, Liu YC (2010) K33-linked polyubiquitination of $T$ cell receptor-zeta regulates proteolysis-independent $\mathrm{T}$ cell signaling. Immunity 33:60-70

Hustad CM, Perry WL, Siracusa LD, Rasberry C, Cobb L, Cattanach BM, Kovatch R, Copeland NG, Jenkins NA (1995) Molecular genetic characterization of six recessive viable alleles of the mouse agouti locus. Genetics 140:255-265

Ivan M, Kondo K, Yang H, Kim W, Valiando J, Ohh M, Salic A, Asara JM, Lane WS, Kaelin WG Jr (2001) HIFalpha targeted for VHLmediated destruction by proline hydroxylation: implications for $\mathrm{O} 2$ sensing. Science 292:464-468

Izquierdo HM, Brandi P, Gomez MJ, Conde-Garrosa R, Priego E, Enamorado M, Martinez-Cano S, Sanchez I, Conejero L, 
Jimenez-Carretero D et al (2018) Von hippel-lindau protein is required for optimal alveolar macrophage terminal differentiation, self-renewal, and function. Cell Rep 24:1738-1746

Jellusova J, Cato MH, Apgar JR, Ramezani-Rad P, Leung CR, Chen C, Richardson AD, Conner EM, Benschop RJ, Woodgett JR et al (2017) Gsk3 is a metabolic checkpoint regulator in B cells. Nat Immunol 18:303-312

Jeon MS, Atfield A, Venuprasad K, Krawczyk C, Sarao R, Elly C, Yang C, Arya S, Bachmaier K, Su L et al (2004) Essential role of the E3 ubiquitin ligase Cbl-b in T cell anergy induction. Immunity 21:167-177

Jiang J, Wang N, Jiang Y, Tan H, Zheng J, Chen G, Jia Z (2015) Characterization of substrate binding of the WW domains in human WWP2 protein. FEBS Lett 589:1935-1942

Jin HS, Park Y, Elly C, Liu YC (2013) Itch expression by Treg cells controls Th2 inflammatory responses. J Clin Invest 123:49234934

Joazeiro CA, Wing SS, Huang $H$, Leverson JD, Hunter T, Liu YC (1999) The tyrosine kinase negative regulator c-Cbl as a RINGtype, E2-dependent ubiquitin-protein ligase. Science 286:309312

Kaelin WG Jr, Maher ER (1998) The VHL tumour-suppressor gene paradigm. Trends Genet 14:423-426

Kallio PJ, Pongratz I, Gradin K, McGuire J, Poellinger L (1997) Activation of hypoxia-inducible factor 1alpha: posttranscriptional regulation and conformational change by recruitment of the Arnt transcription factor. Proc Natl Acad Sci USA 94:5667-5672

Kamura T, Koepp DM, Conrad MN, Skowyra D, Moreland RJ, Iliopoulos O, Lane WS, Kaelin WG Jr, Elledge SJ, Conaway RC et al (1999) Rbx1, a component of the VHL tumor suppressor complex and SCF ubiquitin ligase. Science 284:657-661

Kathania M, Khare P, Zeng M, Cantarel B, Zhang $H$, Ueno $H$, Venuprasad K (2016) Itch inhibits IL-17-mediated colon inflammation and tumorigenesis by ROR-gammat ubiquitination. Nat Immunol 17:997-1004

Kim WY, Kaelin WG (2004) Role of VHL gene mutation in human cancer. J Clin Oncol 22:4991-5004

Kojima H, Gu H, Nomura S, Caldwell CC, Kobata T, Carmeliet P, Semenza GL, Sitkovsky MV (2002) Abnormal B lymphocyte development and autoimmunity in hypoxia-inducible factor 1alpha -deficient chimeric mice. Proc Natl Acad Sci USA 99:21702174

Komander D (2009) The emerging complexity of protein ubiquitination. Biochem Soc Trans 37:937-953

Layman AAK, Sprout SL, Phillips D, Oliver PM (2017) Ndfip1 restricts Th17 cell potency by limiting lineage stability and proinflammatory cytokine production. Sci Rep 7:39649

Lee JH, Elly C, Park Y, Liu YC (2015) E3 ubiquitin ligase VHL regulates hypoxia-inducible factor-1alpha to maintain regulatory T Cell stability and suppressive capacity. Immunity 42:1062-1074

Li Q, Li D, Zhang X, Wan Q, Zhang W, Zheng M, Zou L, Elly C, Lee JH, Liu YC (2018) E3 ligase VHL promotes group 2 innate lymphoid cell maturation and function via glycolysis inhibition and induction of interleukin-33 receptor. Immunity 48(258-270):e255

Liu YC (2004) Ubiquitin ligases and the immune response. Annu Rev Immunol 22:81-127
Lohr NJ, Molleston JP, Strauss KA, Torres-Martinez W, Sherman EA, Squires RH, Rider NL, Chikwava KR, Cummings OW, Morton DH et al (2010) Human ITCH E3 ubiquitin ligase deficiency causes syndromic multisystem autoimmune disease. Am J Hum Genet 86:447-453

Lorick KL, Jensen JP, Fang S, Ong AM, Hatakeyama S, Weissman AM (1999) RING fingers mediate ubiquitin-conjugating enzyme (E2)-dependent ubiquitination. Proc Natl Acad Sci USA 96:11364-11369

Matsumoto M, Baba A, Yokota T, Nishikawa H, Ohkawa Y, Kayama H, Kallies A, Nutt SL, Sakaguchi S, Takeda K et al (2014) Interleukin-10-producing plasmablasts exert regulatory function in autoimmune inflammation. Immunity 41:1040-1051

Matsushita T, Yanaba K, Bouaziz JD, Fujimoto M, Tedder TF (2008) Regulatory $B$ cells inhibit EAE initiation in mice while other $B$ cells promote disease progression. J Clin Invest 118:3420-3430

Maxwell PH, Wiesener MS, Chang GW, Clifford SC, Vaux EC, Cockman ME, Wykoff CC, Pugh CW, Maher ER, Ratcliffe PJ (1999) The tumour suppressor protein VHL targets hypoxiainducible factors for oxygen-dependent proteolysis. Nature 399:271-275

Meng X, Grotsch B, Luo Y, Knaup KX, Wiesener MS, Chen XX, Jantsch J, Fillatreau S, Schett G, Bozec A (2018) Hypoxiainducible factor-1alpha is a critical transcription factor for IL-10producing $B$ cells in autoimmune disease. Nat Commun 9:251

Metzger MB, Hristova VA, Weissman AM (2012) HECT and RING finger families of E3 ubiquitin ligases at a glance. J Cell Sci 125:531-537

Nakashima H, Hamaguchi Y, Watanabe R, Ishiura N, Kuwano Y, Okochi H, Takahashi Y, Tamaki K, Sato S, Tedder TF et al (2010) CD22 expression mediates the regulatory functions of peritoneal $\mathrm{B}-1 \mathrm{a}$ cells during the remission phase of contact hypersensitivity reactions. J Immunol 184:4637-4645

Neumann AK, Yang J, Biju MP, Joseph SK, Johnson RS, Haase VH, Freedman BD, Turka LA (2005) Hypoxia inducible factor 1 alpha regulates $\mathrm{T}$ cell receptor signal transduction. Proc Natl Acad Sci USA 102:17071-17076

O'Connor HF, Lyon N, Leung JW, Agarwal P, Swaim CD, Miller KM, Huibregtse JM (2015) Ubiquitin-Activated Interaction Traps (UBAITs) identify E3 ligase binding partners. EMBO Rep 16:1699-1712

Overacre-Delgoffe AE, Chikina M, Dadey RE, Yano H, Brunazzi EA, Shayan G, Horne W, Moskovitz JM, Kolls JK, Sander C et al (2017) Interferon-gamma drives treg fragility to promote antitumor immunity. Cell 169(1130-1141):e1111

Palazon A, Goldrath AW, Nizet V, Johnson RS (2014) HIF transcription factors, inflammation, and immunity. Immunity 41:518-528

Perry WL, Hustad CM, Swing DA, O'Sullivan TN, Jenkins NA, Copeland NG (1998) The itchy locus encodes a novel ubiquitin protein ligase that is disrupted in a18H mice. Nat Genet 18:143146

Phan AT, Doedens AL, Palazon A, Tyrakis PA, Cheung KP, Johnson RS, Goldrath AW (2016) Constitutive glycolytic metabolism supports CD8(+) T cell effector memory differentiation during viral infection. Immunity 45:1024-1037 
Riling C, Kamadurai H, Kumar S, O'Leary CE, Wu KP, Manion EE, Ying M, Schulman BA, Oliver PM (2015) Itch WW domains inhibit its E3 ubiquitin ligase activity by blocking E2-E3 ligase transthiolation. J Biol Chem 290:23875-23887

Rius J, Guma M, Schachtrup C, Akassoglou K, Zinkernagel AS, Nizet V, Johnson RS, Haddad GG, Karin M (2008) NF-kappaB links innate immunity to the hypoxic response through transcriptional regulation of HIF-1alpha. Nature 453:807-811

Shi LZ, Wang R, Huang G, Vogel P, Neale G, Green DR, Chi H (2011) HIF1alpha-dependent glycolytic pathway orchestrates a metabolic checkpoint for the differentiation of $\mathrm{TH} 17$ and Treg cells. J Exp Med 208:1367-1376

Spits H, Artis D, Colonna M, Diefenbach A, Di Santo JP, Eberl G, Koyasu S, Locksley RM, McKenzie AN, Mebius RE et al (2013) Innate lymphoid cells-a proposal for uniform nomenclature. Nat Rev Immunol 13:145-149

Stebbins CE, Kaelin WG Jr, Pavletich NP (1999) Structure of the VHL-ElonginC-ElonginB complex: implications for VHL tumor suppressor function. Science 284:455-461

Stone EL, Pepper M, Katayama CD, Kerdiles YM, Lai CY, Emslie E, Lin YC, Yang E, Goldrath AW, Li MO et al (2015) ICOS coreceptor signaling inactivates the transcription factor FOXO1 to promote Tfh cell differentiation. Immunity 42:239-251

Venuprasad K, Elly C, Gao M, Salek-Ardakani S, Harada Y, Luo JL, Yang C, Croft M, Inoue K, Karin M et al (2006) Convergence of
Itch-induced ubiquitination with MEKK1-JNK signaling in Th2 tolerance and airway inflammation. J Clin Invest 116:1117-1126

Venuprasad K, Huang H, Harada Y, Elly C, Subramaniam M, Spelsberg T, Su J, Liu YC (2008) The E3 ubiquitin ligase Itch regulates expression of transcription factor Foxp3 and airway inflammation by enhancing the function of transcription factor TIEG1. Nat Immunol 9:245-253

Walmsley SR, Print C, Farahi N, Peyssonnaux C, Johnson RS, Cramer T, Sobolewski A, Condliffe AM, Cowburn AS, Johnson N et al (2005) Hypoxia-induced neutrophil survival is mediated by HIF-1alpha-dependent NF-kappaB activity. J Exp Med 201:105115

Xiao N, Eto D, Elly C, Peng G, Crotty S, Liu YC (2014) The E3 ubiquitin ligase Itch is required for the differentiation of follicular helper T cells. Nat Immunol 15:657-666

Zhang H, Gao P, Fukuda R, Kumar G, Krishnamachary B, Zeller KI, Dang CV, Semenza GL (2007) HIF-1 inhibits mitochondrial biogenesis and cellular respiration in $\mathrm{VHL}$-deficient renal cell carcinoma by repression of C-MYC activity. Cancer Cell 11:407420

Zhu K, Shan Z, Chen X, Cai Y, Cui L, Yao W, Wang Z, Shi P, Tian C, Lou $\mathrm{J}$ et al (2017) Allosteric auto-inhibition and activation of the Nedd4 family E3 ligase Itch. EMBO Rep 18:1618-1630 